\section{Cerebral aneurysm in a patient with Loeys-Dietz syndrome}

Sir,

The Loeys-Dietz syndrome (LDS) is an autosomal dominant genetic disease, characterized by the presence of cerebral, thoracic or abdominal arteries aneurysms or dissections, and skeletal manifestations. There are two different types: Type I with craniofacial manifestations and a triad of arterial tortuosity, hypertelorism, and bifid uvula or palate, and type II with cutaneous manifestations that have no craniofacial abnormalities or cleft palate, but have bifid uvula.

The symptomatic patient was a 46-year-old woman with LDS, who presented with aneurysm rupture of the abdominal aorta, which was surgically resolved and genetic mutation was identified in the resected specimen and blood, confirming the clinically suspected diagnosis. During her stay in the institution, brain magnetic resonance imaging (MRI) was performed, which revealed the presence of two intracranial aneurysms, one located in the carotid artery and one in the vertebral artery, the latter with a wide neck [Figures 1 and 2]. The management was decided by endovascular therapy, thus embolization of the aneurysms was performed. The patient evolved satisfactorily.

In 2005, this rare syndrome was described by Loeys et al. The endovascular management of intracranial aneurysms associated with Loeys-Dietz syndrome has been reported rarely in the literature. ${ }^{[1]}$

Vascular dilatation or dissection of the aorta and/or aneurysms and arterial tortuosity can be detected by angioresonance or an angio view in 95\% of the cases. Patients may have mitral valve prolapse, ectasia of the pulmonary artery, patent ductus arteriosus, atrial septal defects or a bicuspid aortic valve. The skeletal manifestations include: Pectus excavatum or pectus carinatum, scoliosis, joint laxity, like: Positive thumb and wrist signs and/or equine varus feet; arachnodactyly, flat feet, osteoporosis, brachycephaly or trigonocephaly, and may have malar hypoplasia with retrognathia. ${ }^{[2]}$

Cutaneous findings include: Thin skin with very visible venous circulation, friable, and poor healing.

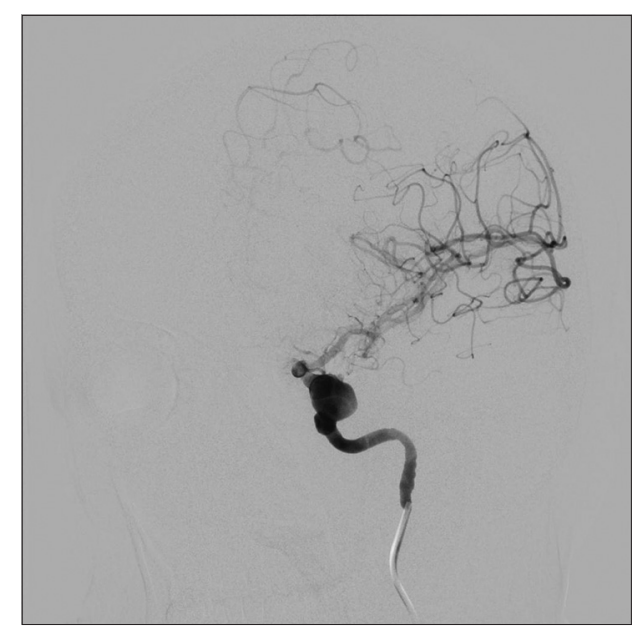

Figure 1: Cerebral angiography, oblique view, with right internal carotid injection showing a cavernous aneurysm

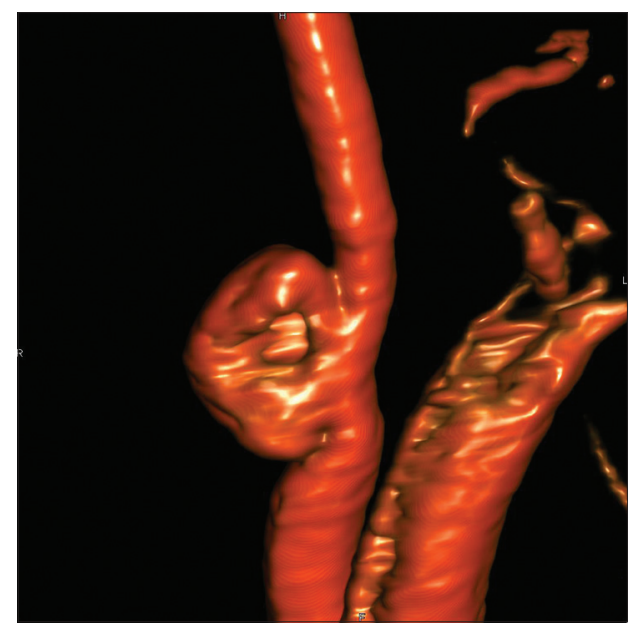

Figure 2: Vertebral angiogram with 3D rotational reconstruction image demonstrating a right vertebral artery aneurysm

Others: Disorders of refraction (myopia), dental enamel dysplasia, and atlantoaxial instability. Spontaneous rupture of the spleen, intestine or uterus during pregnancy, have also been reported. Complications include rupture of aneurysms, with a mean age of 26 years, and a high rate of obstetric complications. ${ }^{[3]}$

The differential diagnosis includes Marfan syndrome, congenital contractural arachnodactyly, mitral valve prolapse, aortic enlargement, skin and skeletal findings, (MASS) syndrome, vascular Ehlers Danlos, and others pathologies. In the Loeys-Dietz syndrome, abdominal aneurysms have been identified in $10 \%$ of patients; the aneurysms may involve the iliac arteries. Diagnosis of the Loeys-Dietz syndrome is based primarily on the clinical features and is confirmed by molecular genetic testing of the TGFBR1 and TGFBR2 genes. The approach to patients 
with intracranial aneurysms, in the context of Loeys-Dietz syndrome, by the endovascular technique, is safe and effective and should be considered in the integrated management strategies for this rare disease. ${ }^{[4-6]}$

\section{Marco Zenteno, Angel Lee ${ }^{1}$, Hernando Raphael Alvis-Miranda ${ }^{2}$, Luis Rafael Moscote-Salazar ${ }^{2}$}

Instituto Nacional de Neurología y Neurocirugía, "Manuel Velasco Suarez", ${ }^{1}$ Hospital Angeles Pedregal, Mexico City, Federal, Mexico, ${ }^{2}$ Universidad de Cartagena, Cartagena, Bolívar, Colombia

Address for correspondence:
Dr. Luis Rafael Moscote-Salazar,
Universidad de Cartagena, Cartagena de Indias, Colombia.
E-mail: mineurocirujano@aol.com

\section{References}

1. Hughes BD, Powers CJ, Zomorodi AR. Clipping of a cerebral aneurysm in a patient with Loeys-Dietz syndrome: Case report. Neurosurgery 2011;69:E746-55.

2. Singh KK, Rommel K, Mishra A, Karck M, Haverich A, Schmidtke J, et al. TGFBR1 and TGFBR2 mutations in patients with features of Marfan syndrome and Loeys-Dietz syndrome. Hum Mutat 2006;27:770-7.

3. Tran-Fadulu V, Pannu H, Kim DH, Vick GW $3^{\text {rd }}$, Lonsford CM, Lafont AL, et al. Analysis of multigenerational families with thoracic aortic aneurysms and dissections due to TGFBR1 or TGFBR2 mutations. J Med Genet 2009;46:607-13.

4. Rahme RJ, Adel JG, Bendok BR, Bebawy JF, Gupta DK, Batjer HH. Association of intracranial aneurysm and Loeys-Dietz syndrome: Case illustration, management, and literature review. Neurosurgery 2011;69:E488-93.

5. Kiliç E, Alanay Y, Utine E, Ozgen-Mocan B, Robinson PN, Boduroğlu K. Arterial tortuosity and aneurysm in a case of Loeys-Dietz syndrome type IB with a mutation p.R537P in the TGFBR2 gene. Turk J Pediatr 2012;54:198-202.

6. Loeys BL, Schwarze U, Holm T, Callewaert BL, Thomas GH, Pannu H, et al. Aneurysm syndromes caused by mutations in the TGF-beta receptor. N Engl J Med 2006;355:788-98.

\begin{tabular}{|l|l|}
\hline \multicolumn{2}{|c|}{ Access this article online } \\
\hline Quick Response Code: & Website: \\
\hline & www.ruralneuropractice.com \\
\cline { 2 - 2 } & \\
\hline
\end{tabular}

